\title{
UJI EKSTRAK DAUN PECUT KUDA (Stachytarphetajamaicencis l) SEBAGAI PENGHAMBAT BAKTERI Staphylococcus aureus
}

\author{
Rokyal Aeni Sufitri ${ }^{1}$, Nurdiana ${ }^{2}$, dan Lutvia Krismayanti ${ }^{3}$ \\ 1Jurusan Tadris IPA Biologi FITK IAIN Mataram \\ ${ }^{2}$ Dosen Jurusan Tadris IPA Biologi FITK IAIN Mataram \\ ${ }^{3}$ Dosen Jurusan Tadris IPA Biologi FITK IAIN Mataram
}

\begin{abstract}
Abstrak
Tanaman pecut kuda (Stachytarpheta Jamaicensis (L) Vahl) merupakan tanaman liar yang tumbuh di tepi-tepi jalan. Tujuan penelitian ini untuk mengetahui ada pengaruh ekstrak daun pecut kuda sebagai penghambat Bakteri Staphylococcus aureusyang dimana biasanya tanaman ini digunakan sebagai obat herbal tradisional karena kandungan senyawa aktif didalamnya yang bermanfaat bagi tubuh. Senyawa aktif yang bermanfaat itu diantaranya adalah fenolik, flavonoid dan antioksidan. Flavonoid, fenolik dan antioksidan merupakan zat alami penangkal kanker. Metode yang digunakan dalam penelitian ini adalah Teknik ekstraksi maserasi. Yang dapat mengekstrak zat aktif secara selektif. Dari hasil penelitian didapatkan bahwa :Daun pecut kuda (Stachytarpheta jamaicencis l) mampu memberikan hambatan dengan diameter zona hambat yang berbeda-beda pada bakteri isolate klinik yang diujikan pada bakteri Staphylococcus aureus dengan taraf signifikan 5\%, hasil analisis menunjukkan bahwa pada konsentrasi $100 \%$ menghasilkan zona hambat tertinggi pada U1 yaitu $13 \mathrm{~mm}$ sedangkan zona hambat terendah yaitu $0 \mathrm{~mm}$ dan $6 \mathrm{~mm}$ yang terdapat pada U1 dan U2 dengan konsentrasi $25 \%$, dengan hasilFhitung $=21.183$ lebih besar dibandingkan dengan $\mathrm{Ftabel}=3.06$, dengan demikian $\mathrm{H}_{\mathrm{O}}$ ditolak yang berarti ada pengaruh ektrak daun pecut kuda (Stachytarpheta jamaicencis l)terhadap pertumbuhan Bakteri (Staphylococcus aureus)
\end{abstract}

Kata Kunci: Ektrak daun Pecut kuda, Stachytarpheta Jamaicensis (L) Vahl, Bakteri Staphylococcus aureus 
ROKYAL AENI SUFITRI, DKK.

\section{PENDAHULUAN}

Pemanfaatan tanaman sebagai obat sudah seumur dengan peradaban manusia. Tumbuhan adalah gudang bahan kimia yang memiliki sejuta manfaat termasuk untuk obat berbagai penyakit. Kemampuan meracik tumbuhan berkhasiat obat dan jamu merupakan warisan turun temurun dan mengakar kuat di masyarakat. Tumbuhan yang merupakan bahan baku obat tradisonal tersebut tersebar hampir di seluruh wilayah Indonesia.

Di hutan tropis Indonesia terdapat 30.000 spesies tumbuhan. Dari jumlah tersebut sekitar 9.600 spesies diketahui berkhasiat obat.Banyak sekali tanaman obat yang ada di Indonesia baik dalam pengobatan tradisional maupun modern. Dimana salah satu tanaman obat yang sudah cukup banyak digunakan adalah tanaman liar pecut kuda. Tanaman ini bisa digunakan untuk mengobati penyakit dalam dan juga luar. Penyakit dalam diantaranya adalah infeksi (batu) saluran kencing, sakit tenggorokan karena radang (faringitis), batuk, rematik, haid tidak teratur, radang hati (hepatitis $A$ ), keputihan (leukore), dan lain-lain sedangkan penyakit luar seperti bisul, radang kulit bernanah, dan luka. Selain itu secara tradisional tanaman pecut kuda digunakan dalam obat rakyat sebagai, pencahar, Ekspektoran vermifuge, Diuretik, Emmenagogue, Diabetes, demam, dan sakit tenggorokan.

Dalam penelitian ini, tanaman pecut kuda digunakan untuk mengambat bakteri penyebab penyakit yaitu Staphylococcus aureusyang dimana mampu menyebabkan penyakit radang tenggorokan dan bisul yang hampir sering dialami. Kenyataan ini sering terlihat di desa Pendem Kecamatan Janapria khususnya desa Kuang, penyakit ini sering kali ditemukan karena keadaan lingkungan yang kurang terawat, makanan yang kurang sehat, makanan yang terlampau pedas dan aktivitas sehari-hari masyarakat Kuang yang harus mencari napkah dengan berbaur dalam lingkungan persawahan sehingga kurangnya perhatian diri terhadap mikroorganisme disekitar lingkungan yang dapat menyebabkan penyakit tersebut. Karena penyakit ini sering timbul, dan harus berobat kerumah sakit, namun kondisi ekonomi

200 BIOTA: Jurnal Tadris IPA Biologi FITK IAIN Mataram 
yang tidak memadai, masyarakat kuang mencoba untuk menyembuhkan penyakit tersebut dengan obat herbal. Salah satunya dengan daun gerigi/ daun pecut kuda (Stachytarpheta jamaicencis $\boldsymbol{L}$ ), yang hasilnya mampu menghilangkan rasa sakit yang dideritanya, tampa harus mengeluarkan biaya yang jumlahnya sangat tinggi.

Sehingga timbul rasa ingin tahu saya sebagai peneliti untuk meneliti daun gerigi/ daun pecut kuda ini, apakah benar tumbuhan pecut kuda ini dapat digunakan sebagai obat tradisional. Tanaman pecut kuda (Stachytarpheta jamaicensis (L) Vahl) didapat dari Surabaya, Jawa Timur, Indonesia. Daun pecut kuda dikenal sebagai salah satu tanaman obat oleh sebagian masyarakat. Keberadaan daun pecut kuda sangat melimpah, akan tetapi masyarakat lebih mengenalnya sebagai tanaman liar atau juga sebagian kecil kalangan masyarakat mengenalnya sebagai tanaman herbal. Oleh karena itu, perlu adanya penelitian mendukung yang menunjukkan dengan jelas potensi tanaman ini sebagai tanaman herbal.

\section{METODE PENELITIAN}

Desain penelitian yang digunakan pada penelitian ini adalah desain penelitian eksperimen untuk menguji ekstra daun Peut Kuda (Stachytarpheta jamaicencis l) sebagai penghambat bakteri isolateklinik. Rancangan penelitian yang digunakan adalah rancangan acak lengkap (RAL) dengan lima kali perlakuan dan empat kali ulangan. Sedangkan pendekatan yang digunakan adalah kuantitatif. Penelitian eksperimen merupakan penelitian yang menggunkan beberapa kelompok yang diberikan perlakuan (treatment) atau stimulus tertentu yang sesuai dengan tujuan penelitian.Penelitian ini menggunakan desain ini karena ingin melihat pengaruh pertumbuhan dari bakteri Staphylococus aureus setalah diberikan ekstrak daun Pecut Kuda (Stachytarpheta jamaicencis I). Penelitian ini menggunakan pendekatan kuantitatif karena data pada penelitian ini berupa angka yang akan dianalisi dengan 
ROKYAL AENI SUFITRI, DKK.

statistik. Data yang digunakan dalam penelitian ini merupakan zona hambatan biakan murni bakteri uji yang diberikan ekstrak daun Pecut Kuda (Stachytarpheta jamaicencis l).

Tabel 1

Desain Penelitian

\begin{tabular}{|c|c|c|c|c|c|c|}
\hline \multirow{2}{*}{ Ulangan (n) } & \multicolumn{5}{|c|}{ Perlakuan } & \multirow{2}{*}{$\begin{array}{l}\text { Total } \\
\text { Ulangan } \\
\text { (T.j) }\end{array}$} \\
\hline & $0 \%(1)$ & $25 \%(\mathrm{II})$ & $50 \%(\mathrm{III})$ & $75 \%(1 \mathrm{~V})$ & $100 \%(\mathrm{~V})$ & \\
\hline 1 & Y1.1 & YII.1 & YIII.1 & Y1V.1 & YV.1 & T.j.1 \\
\hline 2 & $\mathrm{Y}_{1.2}$ & YII.2 & YIII.2 & YIV.2 & YV.2 & T.j.2 \\
\hline 3 & $\mathrm{Y}_{1.3}$ & YII.3 & $Y_{\text {III.3 }}$ & YIV.3 & YV.3 & T.j.3 \\
\hline 4 & Y1.4 & YII.4 & YIII.4 & YIV.4 & YV.5 & T.j.4 \\
\hline Total $\left(Y_{i}\right)$ & Yi 0\% & Yi $25 \%$ & Yi 50\% & Yi 75\% & Yi 100\% & \multirow[b]{2}{*}{$\mathrm{Tij}$} \\
\hline Rerata $(\bar{Y})$ & $\bar{Y} 0 \%$ & $\bar{Y} 25 \%$ & $\bar{Y}_{50 \%}$ & $\bar{Y} 75 \%$ & $\bar{Y} 100 \%$ & \\
\hline
\end{tabular}

(Sumber: skrfsi Huswatun Hasanah.2014) h 30

Keterangan Tabel 3.1

$\mathrm{t} \quad=$ Perlakuan

$\mathrm{n} \quad=$ Ulangan

$\mathrm{Y}_{0 \%} \quad=$ Total perlakuan untuk $0 \%$

$\mathrm{Y}_{25 \%} \quad=$ Total perlakuan untuk $25 \%$

$\mathrm{Y}_{50 \%}=$ Total perlakuan untuk $50 \%$

$\mathrm{Y}_{75 \%}=$ Total perlakuan untuk $75 \%$

$\mathrm{Y}_{100 \%}=$ Total perlakuan untuk $100 \%$

$\mathrm{T}_{\cdot \mathrm{j} .1} \quad=$ Total ulangan 1

$\mathrm{T}_{\mathrm{j} \cdot \mathrm{j} .2}=$ Total ulangan 2

$\mathrm{T}_{\cdot \mathrm{j} \cdot 3}=$ Total ulangan 3

$\underline{\mathrm{T}} \cdot \mathrm{j} \cdot \mathrm{s} \cdot \mathbf{T}=$ Total ulangan 3

$\overline{\mathrm{Y}}^{\mathrm{j} .4} \quad=$ Rata-rata

Tij $\quad=$ Total ulangan dan perlakuan

\section{HASIL PENELITIAN}

Penelitian Ekstrak Daun Pecut Kuda (Stachytarphetajamaicencis l)ini dilakukan pada tanggal 20 Agustus 2015 sampai 22 Agustus 2015 di Unit Riset Biomedik,

202 BIOTA: Jurnal Tadris IPA Biologi FITK IAIN Mataram 
adapun hasil dari penelitian yang sudah dilakukan dengan menggunakan Ekstrak Daun Pecut Kuda (Stachytarphetajamaicencis l)ini berupa zona Bening disekitar sumuran yang ditunjukan pada tabel 2 berikut:

Tabel 2

Hasil diameter Zona Hambat Pada Setiap Perlakuan

\begin{tabular}{|c|c|c|c|c|c|c|}
\hline \multirow{3}{*}{ No } & \multirow{5}{*}{ Perlakuan } & \multicolumn{5}{|c|}{ Diameter zona hambacoccus auteus } \\
\cline { 3 - 7 } & & \multicolumn{5}{|c|}{ Ulanga } \\
\cline { 3 - 7 } & & $\mathrm{U} 1$ & $\mathrm{U} 2$ & $\mathrm{U} 3$ & $\mathrm{U} 4$ & $\mathrm{X}$ \\
\hline 1 & $0 \%$ & 0 & 0 & 0 & 0 & 0 \\
\hline 2 & $25 \%$ & 0 & 6 & 6.5 & 9 & 21. \\
\hline 3 & $50 \%$ & 8 & 9.5 & 9 & 11.5 & 3 \\
\hline 4 & $75 \%$ & 8.25 & 9 & 12 & 10.5 & 39.75 \\
\hline 5 & $100 \%$ & 13 & 10.5 & 12.5 & 11 & 4 \\
\hline
\end{tabular}

Tabel 2 di atas memberikan informasi bahwa zona hambat yang terdapat pada 5 perlakuan dengan 4 ulangan yang diberikan perlakuan daun pecut kuda (Stachytarphetajamaicencis l)dengan konsentrasi yang berbeda- beda. Zona hambat terbentuk pada swab bakteri Staphylococcus aureus mulai terlihat pada konsentrasi $25 \%$ pada U2 hingga $100 \%$ dari 5 perlakuan di atas.

Rata-rata zona hambat yang terbesar terlihat pada konsentrasi $100 \%$ yaitu zona hambat terhadap Staphylococcus aureus sebesar $47 \mathrm{~mm}$, pada tabel diatas dapat diliahat pada diameter zona hambat pada U2 sampai U4 terdapat peningkatan yaitu dari $6 \mathrm{~mm}$ pada konsentrasi $25 \%$ sampai $11 \mathrm{~mm}$ pada konsentrasi $100 \%$, pada perlakuan $50 \%$ dan $75 \%$ zona hambat juga terlihat meningkat.

Pada penelitian ini kontrol positif yang digunakan oleh peneliti adalah cipro, cipro merupakan antibiotik tingkat tinggi yang sudah teruji terlebih dahulu tingkat kemampuan penghambatannya terhadap suatu mikroorganisme penyakit. hal ini digunakan agar zona hambat pada biakan bakteri 
Staphylococcus aureus yang menggunakan konsentrasi daun pecut kuda (Stachytarphetajamaicencis l)dapat dibedakan dengan jelas, sedangkan pada konsentrasi $0 \%$ tidak terdapat zona bening atau tidak terlihat zona hambatnya. Keadaan tersebut dapat dibuktikan kebenarannya melalui grafik rata-rata zona hambat terhadap masing-masing konsentrasi pada perlakuan uji coba daun pecut kuda (Stachytarphetajamaicencis l) pada gambar berikut:

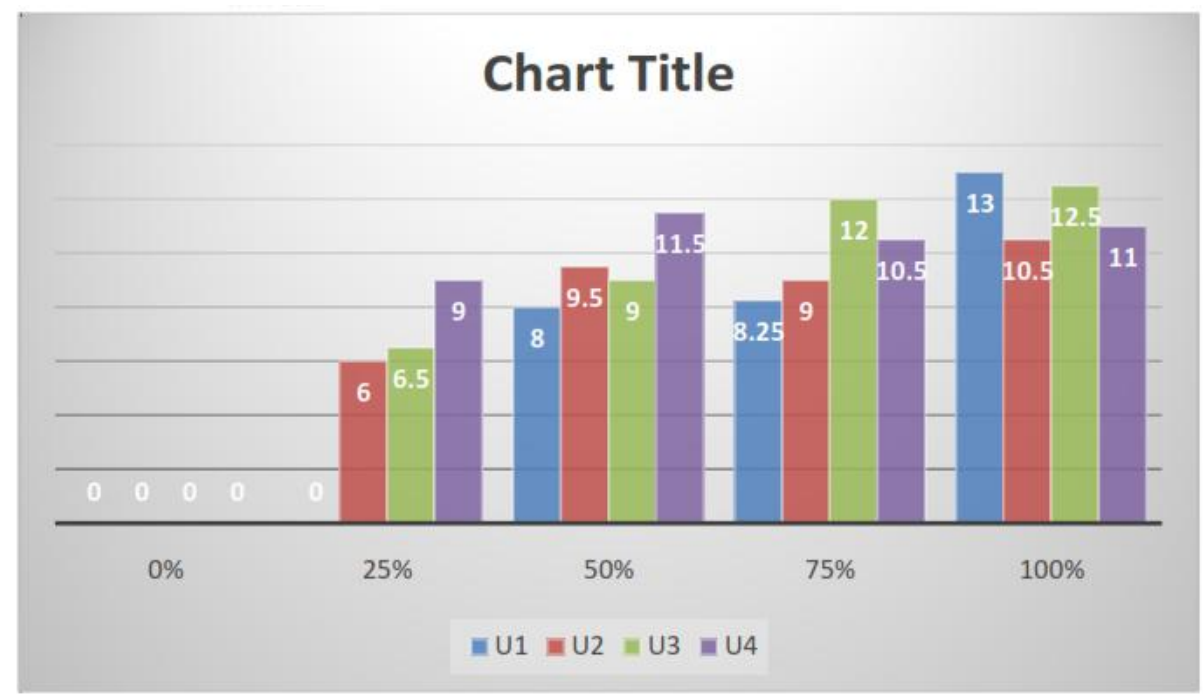

Gambar 1

Grafik Rata-rata Diameter Zona Hambat Bakteri Staphlococcus aureus

Gambar di atas memperlihatkan adanya perbedaan ratarata diameter zona hambatan masing-masing konsentrasi yang menunjukkan adanya perbedaan efek antibakteri pada masing-masing perlakuan. Geafik tersebut menggambarkan bahwa pengaruh konsentrasi ektrak daun pecut kuda (Stachytarphetajamaicencis l)pada koloni Staphylococcus aureus semakin meningkat seiring dengan bertambahnya konsentrasi yang diberikan

204 BIOTA: Jurnal Tad 


\section{Analisis Data}

Data pada tabel 4.1(halaman 42)dianalisis menggunakan Analisis Varians tunggal (One Way Anova), dengan menggunakan SPSS versi 16. Hasil analisis terhadap pertumbuhan bakteri Staphylococcus aureus menunjukkan bahwa Fhitung $=21.183$ lebih besar dari Ftabel $=3.06(5 \%)$. Dengan demikian $\mathrm{H}_{\mathrm{O}}$ ditolak yang berarti ada pengaruh konsentrasi Ekstrak Daun Pecut Kuda (Stachytarphetajamaicencis l)terhadap pertumbuhan bakteri Staphylococcus aureus. Ringkasan hasil analisis dapat dilihat pada tabel 4.2 berikut:

Tabel 3

Ringkasan ANOVA Pertumbungan Bakteri S. aureus dengan menggunakan SPSS Versi 16

\begin{tabular}{|c|c|c|c|c|c|}
\hline \multirow[b]{2}{*}{ ULANGAN } & \multicolumn{4}{|c|}{ ANOVA } & \\
\hline & & & & & \\
\hline & Sum of Squares & df & Mean Square & $\mathrm{F}$ & Sig. \\
\hline Between & 354375 & 4 & 88594 & 21183 & (1) \\
\hline Groups & & & & & \\
\hline Within Groups & 62.734 & 15 & 4.182 & & \\
\hline Total & 417.109 & 19 & & & \\
\hline
\end{tabular}

Tabel 3 di atas menunjukkan bahwa ada pengaruh signifikan ekstrak Daun Pecut Kuda (Stachytarphetajamaicencis l) terhadap pertumbuhan Bakteri Staphylococcus aureus terhadap perlakuan masing-masing konsentrasi yang menggunakan Daun Pecut Kuda (Stachytarphetajamaicencis l). Notasi garis yang digunakan untuk menentukan perlakuan yang mana yang lebih berpengaruh ditunjukkan pada gambar 4.2 berikut: 


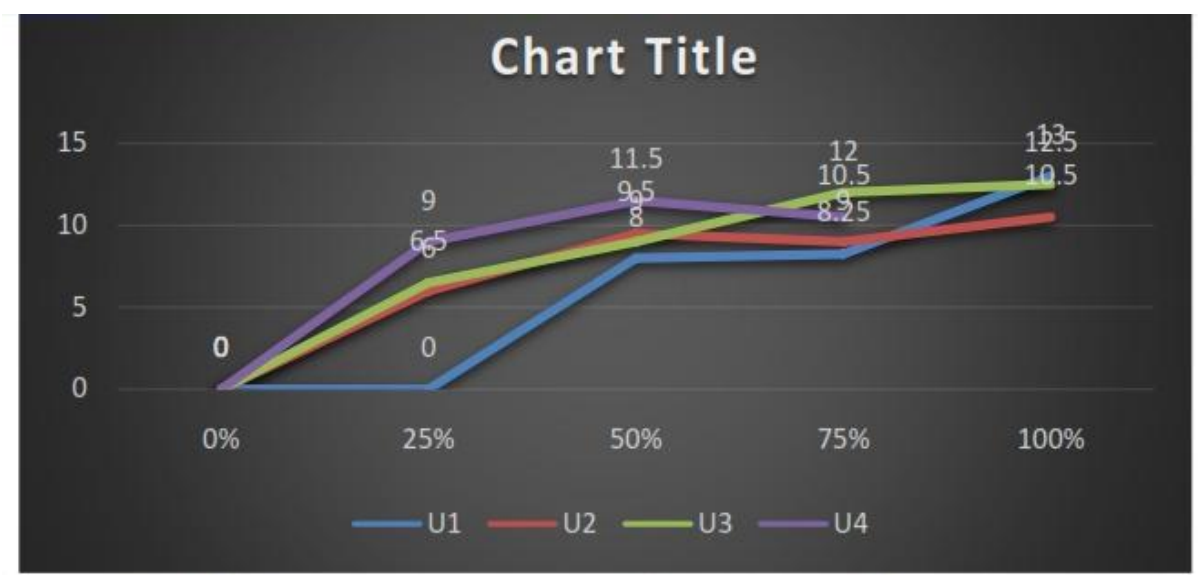

\section{Gambar 2}

Daya Hambat Bakteri Staphylococcus aureus

Gambar di atas menunjukkan gerakan notasi garis daya hambat Ekstrak Daun Pecut Kuda dari konsentrasi 0\% sampai $100 \%$ yang pada konsentrasi $0 \%$ tidak terdapat diameter zona hambat disekitar sumuran, kemudian pada konsentrasi $25 \%$ mulai terlihat pada U2 dan terus meningkat hingga $9 \mathrm{~mm}$ pada U4, sedangkan pada konsentrai $50 \%$ pada U1 meningkat yaitu sekitar $8 \mathrm{~mm}$ dan mencapai $11.5 \mathrm{~mm}$ pada U4, peningkatan zona hambat pada sumuran yang dibuat semakin meningkat pada konsentrasi $75 \%$ dari 8.25 pada U1, $9 \mathrm{~mm}$ pada U2, pada U2 dari kosentrasi 50\% dengan konsentrasi $75 \%$ masih sama, namun meningkat lagi pada U3 10.5 dan $12 \mathrm{~mm}$ pada U4, dan pada konsentrasi $100 \%$ meningkat hingga $13 \mathrm{~mm}$ pada U4. Pada hasil penelitian ini di dapatkan hasil tertinggi diperoleh pada perlakuan $100 \%$. Sedangkan hasil terendah diperoleh pada perlakuan 0\% dengan hasil penghitungan Beda Nyata Terkecil (BNT) 3.018.

206 BIOTA: Jurnal Tadtis IPA Biologi FITK IAIN Mataram 


\section{PEMBAHASAN}

Dari penelitian yang sudah dilakukan terdapat data uji daya antibakteri daun pecut kuda (Stachytarphetajamaicencis l)menunjukkan bahwa ekstrak Daun Pecut Kuda (Stachytarphetajamaicencis l)mampu memberikan hambatan dengan diameter zona hambat yang berbeda-beda pada bakteri isolate klinik yang diujikan (Staphylococcus aureus). Hambatan yang dimaksut didalam penelitian ini dilihat dari zona terang yang terbentuk disekitar sumuran yang telah ditetesi ekstrak Daun Pecut Kuda (Stachytarphetajamaicencis l)

Pengujian daun pecut kuda (Stachytarphetajamaicencis l)pada spesies bakteri uji rata-rata zona hambatan yang tetinggi pada konsentrasi $100 \%$ yaitu zona hambat terhadap Staphylococcus aureus sebesar $13 \mathrm{mmhal}$ ini disebabakan karena pada konsenrasi $100 \%$ ini hanya menggunakan ekstrak Daun Pecut Kuda (Stachytarphetajamaicencis l)tampa adanya campuran aquades. Terlihat bahwa rata-rata diameter zona hambat terhadap Staphylococcus aureus meningkat dengan bertambahnya konsentrasi yang diberikan. Semakin tinggi konsentrasi zat antimikroba maka semakin banyak pula senyawa zat aktif yang terkandung didalam Ektrak Daun Pecut Kuda (Stachytarphetajamaicencis l).

Pada penelitian yang dilakuan peneliti, zat antimikroba Daun Pecut Kuda (Stachytarphetajamaicencis l)mampu memberikan daya hambat yang baik. Hal ini dapat dibuktikan dengan hasil penelitian yang sudah dilakukan, pada medium agar yang peneliti buat medium agar tersebut memiliki standar ketebalan dari standar medium yang biasanya, namun medium agar tersebut tidak mempengaruhi daya hambat yang terbentuk disekitar sumuran, hal ini juga dapat dibuktikan dari hasil penelitian yang sudah dilakukan yaitu adanya peningkatan diameter zona hambat dari U1 sampai U4 yaitu pada konsentarsi $25 \%$ pada U2 mulai terlihat zona bening pada sekitar sumran sekitar $6 \mathrm{~mm}$, U3 $6.5 \mathrm{~mm}$, U4 $9 \mathrm{~mm}$, pada konsentrasi 50\% diameter zona hambatnya mulai terlihat pada U1 yaitu $8 \mathrm{~mm}$, U2 $9.5 \mathrm{~mm}$, U3 $9 \mathrm{~mm}$, U4 $11.5 \mathrm{~mm}$, sedangkan pada konsentrasi 75\% diameter zona hambat juga meningkat yaitu pada U1 $8.25 \mathrm{~mm}$, U2 
9mm, U3 $12 \mathrm{~mm}$ dan U4 $10.5 \mathrm{~mm}$. Dari hasil data tersebut membuktikan bahwa Daun Pecut Kuda (Stachytarphetajamaicencis l)mampu digunakan sebagai salah satu antimikroba, sedangkan pada perlakuan $0 \%$ tidak terdapat zona hambat karena tidak menggunakan ekstrak daun pecut kuda, hal ini digunakan sebagai kontrol negative pada penelitian ini.

Pada penelitian ini pelarut yang digunakan untuk melarutkan Ekstrak Daun Pecut Kuda adalahMetanol 75\%, hal ini peneliti gunakan karena Metanol memiliki kemampuan yang kuat untuk menarik senyawa aktif yang terdapat pada Daun Pecut Kuda (Stachytarphetajamaicencis l)tersebut. Namun pada proses pengenceran yang dilakukan, peneliti menggunakan aquades, akan tetapi hal tersebut tidak mempengaruhi diameter zona hambat disekitar sumuran, sama halnya dengan pengenceran menggunakan Metanol pada uji pendahuluan diameter zona hambat menggunakan metanol tidak terlihat, hal ini menunjukkan bahwa zona hambat dipengaruhi oleh Ekstrak Daun Pecut Kuda (Stachytarphetajamaicencis l).

Pada Uji pendahuluan fitokimia pada daun pecut kuda menunjukkan bahwa di dalamnya mengandung metabolit sekunder saponin, tanin dan flavonoid. Keseluruhan bagian tanaman pecut kuda mengandung senyawa asam klorogenat. Sari daun pecut kuda mengandung senyawa iridoid ipolamiide, glikosida fenilpropanoid, dan verbascosida. Jenis tumbuhan anggota marga Stachytarpheta, dalam hal ini Stachytarpheta indica mengandung senyawa friedelin (termasuk golongan senyawa triterpen).

Secara etnobotani, tanaman pecut kuda berkhasiat sebagai penghilang nyeri, obat lambung, obat cacing, obat bengkakbengkak, pelancar air seni, penurun tekanan darah, pencahar, pelancar laktasi, penenang, obat sakit perut, dan obat sesak nafas. Tanaman ini juga digunakan untuk alergi dan kondisi respiratori seperti batuk, flu, asma, bronkitis, dan yang lain. Selain itu juga digunakanuntuk gangguan pencernaan seperti indigesti, ulcer, konstipasi, dispepsia, dan digesti lemah. Untuk pasien yang sedang hamil dan pasien hipotensi tidak dianjurkan untuk

208 BIOTA: Jurnal Tadris IPA Biologi FITK IAIN Mataram 
mengkonsumsi tanaman ini karena bersifat abortif dan hipotensif.

Dari hasil penelitian yang dipaparkan di atas dan penelitian yang peneliti lakukan di Unit Riset Biomedik menunjukkan bahwa daun pecut kuda (Stachytarphetajamaicencis l) bisa dijadikan salah satu alternative obat herbal sebagai penghilang nyeri, obat lambung, obat cacing, obat bengkak- bengkak, pelancar air seni, penurun tekanan darah, pencahar, pelancar laktasi, penenang, obat sakit perut, dan obat sesak nafas, alergi dan kondisi respiratori seperti batuk, flu, asma, bronchitis. Pada penelitian yang dilakukan oleh peneliti daun pecut kuda (Stachytarphetajamaicencis l) mampu menjadi solusi penyakit yang ditimbulkan oleh bakteri Staphylococcus aureus.

\section{PENUTUP}

\section{Kesimpulan}

Berdasarkan Rumusan Masalah dan analisi data hasil penelitian yang sudah dilakukan maka dapat ditarik kesimpulan bahwa Ada pengaruh ektrak daun pecut kuda (Stachytarpheta jamaicencis l)terhadap pertumbuhan bakteri Staphylococcus aureus berupa terbentuknya zona bening disekitar sumuran yang dibuat oleh peneliti,dengan daya hambat yang paling tinggi diperoleh pada zona hambat dengan konsentrasi $100 \%$ yaitu sebesar $13 \mathrm{~mm}$.

Dari hasil penghitungan manual dan SPSS bahwa Fhitung lebih besar yaitu 21.183 dibandingkan dengan Ftabel3.06, hal ini menunjukkan bahwaHo ditolak $\mathrm{H}_{\mathrm{a}}$ diterima dengan demikian daun pecut kuda (Stachytarpheta jamaicencis l) bisa digunakan sebagai penghambat bakteri panyakit khususnya yang peneliti teliti yaitu bakteri Staphylococcus aureus

\section{Saran}

1. Perlu diadakan penelitian lebih lanjut bagi peneliti selanjutnya untuk mengetahui kandungan senyawa aktif yang 
paling banyak terkandung didalam daun pecut kuda (Stachytarpheta jamaicencis l).

2. Untuk peneliti selanjutnyaperlu diadakan penelitian terkait dengan efek samping dari daun pecut kuda perlunya penelitian lebih lanjut, agar mampu dikonsumsi dengan baik.

3. Perlunya penelitian lebih lanjut terkait bakteri apa saja yang mampu di hambat oleh daun pecut kuda (Stachytarpheta jamaicencis l).

\section{DAFTAR FUSTAKA}

Ahmad aziz salim basarin. Seribu Seratus Hadist Terpilih Sinar Ajaran Muhamad Cetakan24, Jakarta: Gema Insani Press, 2007.

Atiqa Ulfa, " Pengaruh konsentrasi ekstrak daun bandotan (Ageratum conyzoides) terhadap petumbuhan bakteri Staphylococcus aureus dan Staphylococcus epidermidis " Skrifsi, IAIN Mataram, Mataram, 2013.

Calista." Ekstraksi Senyawa Aktif Dari Tumbuhan Liar Pecut Kuda Sebagai Obat Herbal Antikanker Menggunakan Metode Ramah Lingkungan", Jurnal Teknik Kimia Fakultas Tehnik Universitas Katolik Widya Mandala Surabaya, 2013.

Gembong Tjitrosoepomo. Taksonomi Tumbuhancet 10. Yogyakarta: Gajah Mada

University Press, 2010.

Jawetz, Mikrobiologi Kedokteran Edisi 20, (Jakarta: Salemba Medika,1996), Jurnal Latar Belakang Pecut Kuda.

Koes Iranto. Mengenal Dunia Bakteri. Bandung : Pringgandani, 2006. Koes Iranto. Mikrobilogi jilid1. Bandung: Yrama Widya,2006.

https://www.gogle.com/searet?q=pengertiandanpenghambat Koes Irianto. Mikrobiologi Jilid 1. Bandung: Yrama Widya, 2006.

Moch Agus Kresno Budiyanto, Mikrobiologi Terapan, Malang:UMM Pres,2004. Nanang Martono.Metode Penelitian Kuantitatif, Jakarta: Rajawali Press,2012.

210 BIOTA: Jurnal Tadris IPA Biologi FITK IAIN Mataram 